\title{
Bridging the Research-Practice Divide in Youth Psychotherapy: The Deployment-Focused Model and Transdiagnostic Treatment
}

\author{
John R. Weisz \\ Department of Psychology, William James Hall, Harvard University, Cambridge, MA, USA
}

\section{Keywords}

Youth · Children · Adolescents · Psychotherapy .

Empirically supported treatment . Transdiagnostic

\section{Summary}

Five decades of research have produced scores of empirically tested psychotherapies for youths who have mental health problems and disorders. These empirically supported treatments (ESTs), most of them focused on single disorders or single problem domains (e.g., depressive disorders), have shown substantial effects in randomized controlled efficacy trials. However, the ESTs do not fare as well when tested against usual clinical care with clinically referred youths treated in clinically representative conditions. One reason may be that referred youths and their clinical care contexts are sometimes more complex than the ESTs. For example, most youths referred for treatment have multiple problems and disorders, and their treatment needs shift over time. To address the differences between efficacy research conditions and clinical practice, we have proposed a deployment-focused model of treatment development and testing, recommending research that focuses on the kinds of individuals and intervention contexts for which the treatments are ultimately intended. Our work with colleagues consistent with the deployment-focused model has led to a transdiagnostic intervention approach, Child STEPs. STEPs uses an integrative modular treatment protocol derived from the psychotherapy evidence base, with treatment guided by frequent feedback to clinicians on youth treatment response. In a multisite randomized trial of this approach, applied to youths with anxiety, depression, and conduct problems, STEPs markedly outperformed usual clinical care on measures of clinical symptoms and diagnosis. The findings illustrate the potential of the deployment-focused approach to narrow the gap between clinical science and everyday clinical care.
Schlüsselwörter

Jugendliche $\cdot$ Kinder $\cdot$ Heranwachsende $\cdot$ Psychotherapie

Empirisch gestützte Behandlung · Transdiagnostisch

\section{Zusammenfassung}

Die Überbrückung der Kluft zwischen Forschung und Praxis in der Kinder- und Jugendlichenpsychotherapie mittels eines entwicklungsbezogenen Models und transdiagnostischer Behandlung In den letzten 50 Jahren wurden zahlreiche Psychotherapieansätze für Jugendliche mit psychischen Störungen entwickelt und empirisch untersucht. Für die meisten dieser empirisch gestützten Behandlungen (empircally supported treatments, ESTs), die sich vor allem auf einzelne Störungsbilder oder Problembereiche (z.B. depressive Störungen) beziehen, konnten in randomisierten kontrollierten Wirksamkeitsstudien bedeutsame Effekte gezeigt werden. Unter typischen klinischen Bedingungen konnte für empirisch gestützte Behandlungen bisher jedoch noch keine deutliche Überlegenheit gegenüber der klinischen Standardbehandlung von klinisch auffälligen Jugendlichen nachgewiesen werden. Ein Grund dafür könnte darin liegen, dass klinisch auffällige Jugendliche und deren klinische Behandlungskontexte eine höhere Komplexität aufweisen als die empirisch gestützten Behandlungen. Das heißt, die meisten klinisch auffälligen Jugendlichen leiden unter verschiedenen Problemen und Störungen, sodass sich der Behandlungsschwerpunkt im Zeitverlauf verändern kann. Um den Unterschieden zwischen den Bedingungen der Wirksamkeitsforschung und der klinischen Praxis Rechnung zu tragen, wurde ein entwicklungsbezogenes Modell (deployment-focused model) zur Untersuchung des Behandlungsverlaufes entwickelt, das die individuellen Behandlungs- und Kontextbedingungen berücksichtigt, für die die Behandlungen letztendlich entwickelt wurden. In Zusammenarbeit mit anderen Kollegen und konsistent mit dem entwicklungsbezogenen Modell haben wir einen transdiagnostischen Behandlungsansatz entwickelt: Child STEPs. STEPs verwendet ein evidenzbasiertes integratives, modulares Behandlungsprotokoll das die Therapie durch ein regelmäßiges Feedback der Behandlungsfortschritte der Jugendlichen an den Kliniker begleitet. In einer multizentrischen randomisierten Studie dieses Behandlungsansatzes für Jugendliche mit Angst- und depressiven Problemen bzw. Verhaltensauffälligkeiten war STEPs der klinischen Standardbehandlung in Bezug auf die klinische Symptomausprägung und Diagnose deutlich überlegen. Die Ergebnisse zeigen das Potenzial des entwicklungsbezogenen Ansatzes, die Lücke zwischen klinischer Forschung und alltäglicher klinischer Praxis zu verringern.

\section{KARGER


Fig. 1. Mean effect sizes in 2 widely-cited broadbased meta-analyses of adult psychotherapy trials ( 2 bars on left), broad-based meta analyses of youth psychotherapy trials ( 4 bars in the middle), and 2 meta-analyses of youth psychotherapy trials comparing empirically supported treatments to usual clinical care (2 bars on the right bar).

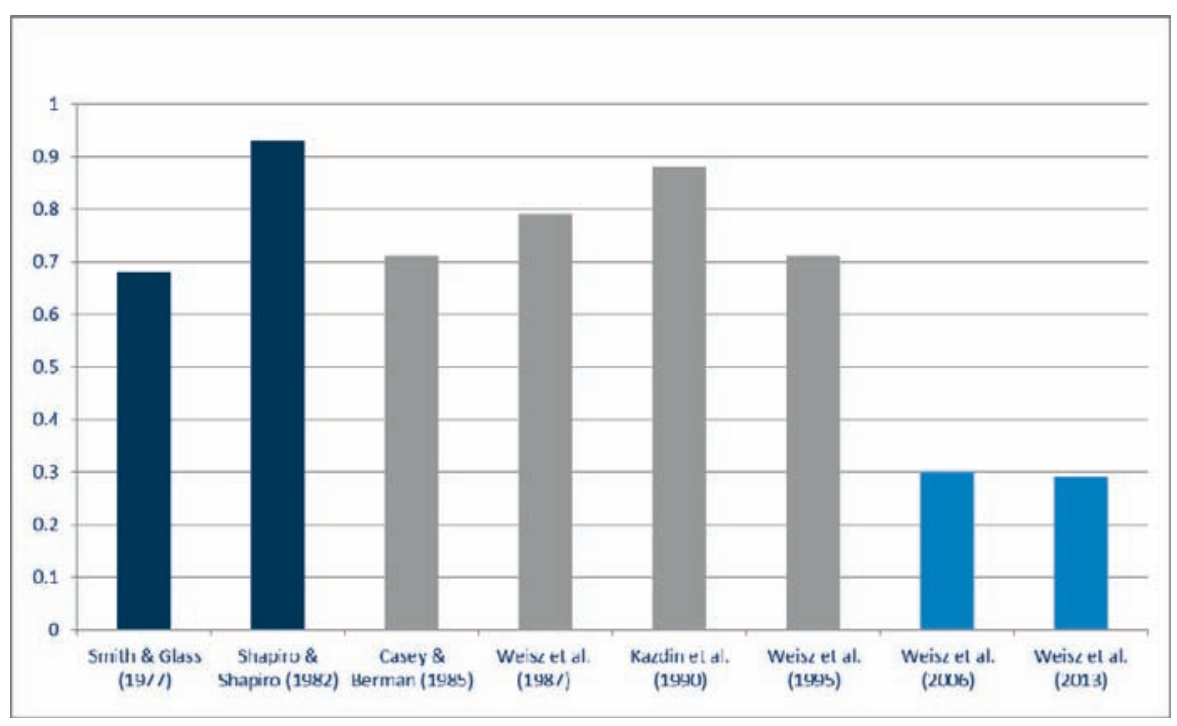

\section{Introduction}

Efforts to help children and adolescents (herein, 'youths') are as ancient as parenthood. Models and methods of helping have been shaped over millennia by religious teachings, classical philosophy, medicine, and diverse other disciplines and perspectives. The professional approach called youth psychotherapy is a relative newcomer, emerging - some would say - when Sigmund consulted with the father of a very anxious 'Little Hans' and conducted analysis with his own daughter. Psychoanalysis ushered in the era of psychology's grand theories, competing treatment models proliferated, and eventually behaviorism [e.g., Jones, 1924], cognitive and cognitive-behavioral methods [e.g., Meichenbaum and Goodman, 1971] as well as diverse alternative approaches took shape. At the turn of this century, Kazdin [2000] tallied 551 different named therapies used with children and adolescents.

Like youth psychotherapy, therapy research has also been transformed over the decades. Research in the mid-1900s largely consisted of quasi-experimental studies of vaguely-defined treatments. Prominent researchers of the time - focusing on studies of adults and youths - concluded that psychotherapy might not be effective at all [Eysenck, 1952; Levitt, 1963]. But methods grew more sophisticated, with increasingly rigorous randomized controlled trials (RCTs) testing better-documented, manual-guided therapies. Meta-analyses of the youth RCTs [e.g., Casey and Berman, 1985; Kazdin et al., 1990; Weisz et al., 1987, 1995] suggested that psychotherapy did outperform various control groups and showed substantial mean effects, within the range of effects found for adult psychotherapy (fig. 1). Task forces have applied systematic criteria to the accumulating RCTs, to identify specific 'empirically supported treatments' (ESTs) for youths [e.g., Silverman and Hinshaw, 2008]. The specific criteria for the EST designation differ somewhat across review groups, but most require support from multiple RCTs, ideally conducted by independent researchers. Lists of approved treatments are now proliferating. The U.S.
National Registry of Evidence-Based Programs and Practices (www.nrepp.samhsa.gov/ViewAll.aspx) lists more than 300 'evidence-based' interventions, more than 200 for children and adolescents.

\section{Implementation Challenges}

A broad multinational movement is now underway to implement ESTs in everyday treatment settings. We have participated in this movement, but along the way we encountered 'an inconvenient truth': Treatments that fare well in traditional RCTs do not always seem quite so strong when implemented in everyday clinical practice. We heard this in conversations with practitioners, and we found it to be true in our own effectiveness trials testing cognitive behavioral therapy (CBT) for anxiety and for depression against usual clinical care in youth community mental health clinics [Southam-Gerow et al., 2010; Weisz et al., 2009]. We also conducted 2 meta-analyses of RCTs that had tested youth ESTs in more clinically representative contexts, pitting the ESTs against usual care [Weisz et al., 2006, 2013]. Both meta-analyses showed highly variable outcomes, with numerous studies in which ESTs did not outperform usual care, and markedly lower mean effect sizes than studies using more traditional designs that compared ESTs to waitlist or experimenter-constructed control groups (fig. 1). In fact, the mean effect sizes in our EST versus usual care meta-analyses (0.30 and 0.29 , respectively) corresponded to a probability of only 0.58 (vs. chance at 0.50 ) that a randomly selected youth treated with an EST would be better off after treatment than a randomly selected youth who received usual care. In our most recent meta-analysis [Weisz et al., 2013] we found that ESTs did not significantly outperform usual care in studies with clinically referred youths, or in studies with youths impaired enough to qualify for a formal diagnosis. This is worrisome, because these are target groups for which EST success should have very high priority. 
These disappointing findings may be explained in part by examining the kind of research that has produced most youth ESTs. A close look reveals that the research is not very representative of clinical practice conditions [Weisz et al., 2005]. The studies are generally high in internal validity but low in external validity, or clinical representativeness. In a recent examination of 461 youth RCTs, spanning the 1960s through the most recent decade, we found that only $2.1 \%$ of all the groups were described by authors as involving clinically referred clients, treated by practitioners, in practice settings [Weisz et al., 2014]; even for studies in the most recent decade, the figure was only $4.5 \%$. These figures reflect, in part, the extent to which treatment research has been structured to control 'noise', particularly the kinds that might compromise treatment success.

Conducting research under such conditions has very clear advantages experimentally. Precision and control are amplified by using participants who are recruited (not referred) and who have the target disorder without potentially interfering comorbidities; therapists who are hired and paid by the researcher; and settings the researcher can control (e.g., university lab clinic). However, the emphasis on investigator control may also be a double-edged sword. On the one hand, investigator control may support scientific rigor, which we clinical researchers value. On the other hand, exerting investigator control may have reduced opportunities to learn how to navigate the real-life conditions of actual clinical practice - the very conditions that are minimized in clinical research. It would be an interesting paradox if research designed to improve clinical care has produced treatments that do not fit - and may not cope so well with - the very clinical care it was intended to improve. The risk is that when ESTs are introduced into everyday practice contexts, those treatments whose research base has not exposed them to real-world conditions may be hampered by those conditions, and treatment outcomes may suffer.

The research on youth psychotherapy, to date, has produced ESTs that are mainly (a) designed for single disorders (or very homogenous clusters - e.g., depressive disorders), even though most clinically referred youths have comorbid conditions and multiple co-occurring problems; (b) linear in design, with sessions organized in a prescribed order - even though everyday clinic treatment is often non-linear, with unexpected events and multiple shifts in treatment needs; and (c) tested when delivered by the researcher's own students or employees, under conditions designed by the researcher, even though actual clinical implementation will not be done that way. As we have seen, these ESTs tend not to show very consistent or substantial effects in more clinically representative conditions when compared to usual care [Weisz et al., 2006, 2013].

\section{The Deployment-Focused Model of Treatment Development and Testing}

These findings are not what either clinicians or clinical scientists would want to see. Both groups have a shared interest in seeing scientifically tested treatments fit into and perform well within the ecosystem of clinical care. Toward that end, we have proposed a deployment-focused model of treatment development and testing [Weisz, 2004; Weisz and Gray, 2008]. The model calls for an emphasis on developing and testing interventions in the kinds of contexts, and with the kinds of therapists and clients, for which the interventions are ultimately intended, and for testing them against usual care. Such research could - and should - look very much like traditional RCTs in terms of design and rigor, but the emphasis on clinical representativeness should generate comparatively more externally valid evidence on intervention effects, moderation, mediation, and mechanisms of change, and ideally more practice-ready interventions. The deployment-focused model reflects a simple notion: ESTs that have been designed for, refined to fit, and tested within clinical care contexts against the usual interventions found there, should be more effective in those contexts than ESTs that have not.

\section{Development and Testing of the Child STEPs Treatment Model}

Working within the deployment-focused model over the years has taught us a lot about the conditions of clinical care within which ESTs must be robust to succeed [Weisz et al., 2013]. Our most recent effort, with colleagues in the Research Network on Youth Mental Health, led to creation of a treatment approach that is designed to address the comorbidity and ongoing shifts in treatment needs that are so common in everyday youth clinical care, but not likely to be well-addressed by single-disorder ESTs. This approach, called Child STEPs (Child System and Treatment Enhancement Projects), includes (a) a transdiagnostic treatment manual, and (b) a clinical information system that gives therapists frequent information on youth treatment response, to guide their decision-making.

The treatment manual includes a collection of modules - i.e., concise descriptions of common components of ESTs for youth problems involving anxiety, depression, and conduct problems. The manual also includes flowcharts to inform therapists' decisions about which modules to use, and when. Through this transdiagnostic manual [Chorpita and Weisz, 2009; Weisz and Chorpita, 2011] we sought to provide therapists with broader, more flexible coverage of youth problems and disorders than most ESTs do, while retaining core components of the ESTs that clinical scientists have tested so extensively over the decades.

The current version of the manual, 'Modular Approach to Therapy for Children with Anxiety, Depression, Trauma, or Conduct Problems' (MATCH-ADTC [Chorpita and Weisz, 2009]), includes 33 modules; flowcharts guide therapists' decisions about module selection and timing. Because a treatment episode may begin with a focus on anxiety, post-traumatic stress, depression, or conduct, there is 1 flowchart for each problem domain. The flowcharts also include detours the therapist may take if there is interference - e.g., if treating problems of one type is hampered by problems of another type. The decision-making required for MATCH treatment 
is informed by brief weekly youth and caregiver assessments that give the therapist ongoing feedback on the youth's treatment response. This assessment strategy, the second element of the Child STEPs approach, provides information therapists need to navigate across modules, within and across the problem areas covered by MATCH.

We tested the Child STEPs approach in an RCT with clinicallyreferred youths from 10 clinical service programs. The treatment conditions included (a) Child STEPs, (b) usual care, and (c) standard treatment manuals for anxiety (CBT), depression (CBT), and conduct problems (behavioral parent training). The youths were treated by practitioners who worked in community clinics and schools; the practitioners were randomized to 1 of the 3 treatment conditions. Our findings at post-treatment showed Child STEPs treatment to be significantly and markedly more effective than usual care and standard manuals [Weisz et al., 2012], and findings of our 2-year follow-up showed Child STEPs to be significantly and markedly more effective than usual care [Chorpita et al., 2013]. In both post-treatment and follow-up analyses, the mean effect sizes of the STEPs versus usual care comparison on youth plus caregiver measures was 0.55 at post-treatment and 0.58 at followup, markedly higher than the mean effects for ESTs versus usual care in the 2 meta-analyses reported earlier ( 0.29 and 0.30 [Weisz et al., 2006, 2013]). This suggests that treatment with the STEPs approach may take us one step closer to bridging the gap between psychotherapy research and practice.

\section{Conclusions and Future Directions}

The conditions of most traditional youth psychotherapy research do not appear to match up well with the conditions of youth psychotherapy in clinical practice. The resulting gap may limit the goodness-of-fit between many research-derived treatments - even the ESTs - and real-world implementation settings; poor fit may limit the effectiveness of these treatments in clinical care. Applying the deployment-focused model may help investigators bridge that divide. Research with the Child STEPs model suggests the potential of a clinically-oriented approach to treatment development and testing. We are continuing to test the Child STEPs model in different contexts and conditions, and to develop alternative approaches to research-derived but clinician-friendly psychotherapy, all carried out within the deployment-focused model. In this work we hope to engage an ever-larger cohort of clinical scientist colleagues in building practice-ready treatments that are agile and potent, and a rigorous evidence base on their effects.

\section{Disclosure Statement}

Some of the research reported here was supported by grants from the U.S. National Institute of Mental Health (MH57347, MH068806, MH085963), the Norlien Foundation, the MacArthur Foundation, and the Annie E. Casey Foundation. The author receives royalties for some of the published works cited in this paper, but is not aware of any conflict of interest.

\section{References}

Casey RJ, Berman JS: The outcome of psychotherapy with children. Psychol Bull 1985;98:388-400.

Chorpita BF, Weisz JR: MATCH-ADTC: Modular Approach to Therapy for Children with Anxiety, Depression, Trauma, or Conduct Problems. Satellite Beach, PracticeWise, 2009.

Chorpita BF, Weisz JR, Daleiden EL, et al.: Long term outcomes for the Child STEPs randomized effectiveness trial: a comparison of modular and standard treatment designs with usual care. J Consult Clin Psychol 2013; 81:999-1009.

Eysenck HJ: The effects of psychotherapy: an evaluation. J Consult Psychol 1952;16:319-324.

Jones MC: The elimination of children's fears. J Exper Psychol 1924;7:382-390.

Kazdin AE: Psychotherapy for Children and Adolescents: Directions for Research and Practice. New York, Oxford University Press, 2000.

Kazdin AE, Bass D, Ayers WA, Rodgers A: Empirical and clinical focus of child and adolescent psychotherapy research. J Consult Clin Psychol 1990;58:729-740.

Levitt EE: Psychotherapy with children: a further evaluation. Behav Res Ther 1963;60:326-329.

Meichenbaum DM, Goodman S: Training impulsive children to talk to themselves: a means of developing selfcontrol. J Abnor Psychol 1971;77:115-126.

-Shapiro DA, Shapiro D: Meta-analysis of comparative therapy outcome studies: a replication and refinement. Psychol Bull 1982;92:581-604.
Silverman WK, Hinshaw SP: The second special issue on evidence-based psychosocial treatments for children and adolescents: a 10-year update. J Child Adol Clin Psychol 2008;37:1-7.

Smith ML, Glass GV: Meta-analysis of psychotherapy out come studies. Am Psychol 1977;32:752-760.

Southam-Gerow MA, Weisz JR, Chu BC, McLeod BD, Gordis EB, Connor-Smith JK: Does CBT for youth anxiety outperform usual care in community clinics? An initial effectiveness test. J Am Acad Child Adol Psychiatry 2010;49:1043-1052.

Weisz JR: Psychotherapy for Children and Adolescents: Evidence-based Treatments and Case Examples. New York, Cambridge University Press, 2004.

Weisz JR, Chorpita BF: Mod squad for youth psychotherapy: restructuring evidence-based treatment for clinical practice; in Kendall PC (ed): Child and Adolescent Therapy: Cognitive-behavioral Procedures, ed 4. New York, Guilford Press, 2011, pp 379-397.

Weisz JR, Chorpita BF, Palinkas L, Schoenwald SK, Miranda J, Bearman SK: The Research Network on Youth Mental Health. Testing standard and modular designs for psychotherapy treating depression, anxiety, and conduct problems in youth: a randomized effectiveness trial. Arch Gen Psychiatry 2012;69:274-282.

Weisz JR, Gray JS: Evidence-based psychotherapies for children and adolescents: data from the present and a model for the future. Child and Adolescent Mental Health 2008;13:54-65.

Weisz JR, Jensen-Doss AJ, Hawley KM: Youth psychotherapy outcome research: a review and critique of the evidence base. Ann Rev Psychol 2005;56:337-363.
Weisz JR, Jensen-Doss A, Hawley KM: Evidence-based youth psychotherapies versus usual clinical care: a meta-analysis of direct comparisons. Am Psychol 2006;61: 671-689.

Weisz JR, Kuppens S, Eckshtain D, Ugueto AM, Hawley KM, Jensen-Doss A: Do evidence-based youth psychotherapies outperform usual clinical care? A multilevel meta-analysis. JAMA Psychiatry 2013;70:750-761.

Weisz JR, Ng MN, Bearman SK: Odd couple? Re-envisioning the relation between science and practice in the dissemination-implementation era. Clin Psychol Sci 2014;2:58-74.

Weisz JR, Southam-Gerow MA, Gordis EB, Connor-Smith JK, Chu BC, Langer DA, Weiss B: Cognitive-behavioral therapy versus usual clinical care for youth depression: an initial test of transportability to community clinics and clinicians. J Consult Clin Psychol 2009;77: 383-396.

Weisz JR, Ugueto AM, Cheron DM, Herren J: Evidencebased youth psychotherapy in the mental health ecosystem. J Clin Child Adol Psychol 2013;42:274-286.

Weisz JR, Weiss B, Alicke MD, Klotz ML: Effectiveness of psychotherapy with children and adolescents: a metaanalysis for clinicians. J. Consult Clin Psychol 1987;55: 542-549.

Weisz JR, Weiss B, Han SS, Granger DA, Morton T: Effects of psychotherapy with children and adolescents revisited: a meta-analysis of treatment outcome studies. Psychol Bull 1995;117:450-468. 